\title{
The normal situation for China's economic and social development
}

\author{
Yongjian ZHAO \\ Postdoctoral Programme of China Center for Industrial Security Research \\ Beijing Jiaotong University \\ Beijing , China
}

\begin{abstract}
Human society faces with development issues from the outset. The human has experienced a deepening and comprehensive process about development issues. The scientific concept of development is the latest achievements about Chinese social development issues. The development of science is the balanced development with fairness and efficiency, which is the true embodiment of the scientific concept of development. The only economic development or only social equitable development is not proper development for a socialist society.
\end{abstract}

Keywords- Development, Scientific Development, Balanced Development with Fairness and Efficiency.

\section{INTRODUCTION}

"Development" is a historical concept throughout the human history. Meaning of development is quite rich and complex, and it has different connotations in different areas. In ancient times, there is no word "development", broadly in line with the development of movement, change synonymous. Development, in its general sense, refers to the combination of the starting point in a certain "fat" and "Show", the former is referring to the vertical development, the latter is referring to the lateral extensions. However, the development theory of development they are talking about not just stays on this general understanding. In the field of human society, it has a rich and unique content, which cannot simply be generalized. Although the development of human society continues, people around the world are also the development of practice; however, the real importance for the development of a comprehensive long time is not to think. Human development issues attracted worldwide attention, but it is something after the mid-20th century.

\section{20TH CENTURY DEVELOPMENT}

The awareness of development of Western scholars and government has gone through three stages: First, the economic growth is equivalent to the stage of development that economic growth, the GNP is to develop. After World War II, everything is undone, when the development concept for the development of industrialized countries is to copy to the accumulation of physical capital as the core to the gross domestic product (GDP) for the evaluation of the development of basic indicators, and it is ultimately to the development of attributed to the accumulation of material goods. Second, the phase of reflection on economic growth, economic growth began as a simple development of deep reflection. Accelerate economic growth in the world. There is consensus on national development, humankind has created unprecedented economic growth miracle. In the 20th century, people from the one-sided have the pursuit of GDP growth to pay attention to the coordinated development of economy, society, resources and the environment, by focusing on the development of material to focus on comprehensive human development, reflecting the evolving concept of human development and deepening. Deepen and enrich the concept of development continue to guide human right, comprehensive understanding and practice of development. However, since the 1980s the development practice in many countries shows that: Only in a small number of developing countries, modernization has made important progress; most developing countries are caught stagnation and recession. In the 1980s, known as the "lost decade" of the 1990s has been called the "crisis of the decade." In 2003, "Human Development Report" shows: in the 1990s, 54 countries have per capita incomes decline, 21 national human development indicators have fallen. This situation cannot but arouse renewed reflection on the contemporary development model and development concept. In other words, although the human development issues for a deeper understanding of the concept of development continue to enrich and be perfect. However, the development of this practice carried out, it is also problematic, unsatisfactory. Although, in the 20th century, humankind has made tremendous developments, the creation of wealth has even more than the sum of the previous era of wealth creation for all. Undoubtedly, the development in the 20th century, there are significant drawbacks: First, deny regularity of social development, the second is the lack of human and social development for the scientific understanding of the intrinsic relationship, although the overall development of the people began to focus on coordinated development. In other words, it does not really recognize and seize the development of the law.

\section{SCIENTIFIC DEVELOPMENT}

Human society needs a more open, forward-looking development perspective to understanding approach to development. The famous professor of development economics Mr. Dudley Hills raised fundamental questions of the meaning of development. "The problem of development of a country is: how poverty unemployment how inequality What if these three areas were significantly reduced, then there is no doubt that the country is in the development stage if these central issues? In one or two problems worse, especially three issues are getting worse, then called for the development of this situation is confusing, even the per capita income has doubled." 
Understanding of the Communist Party of China and the development of the law of socialist construction is with the development of the practice of deepening. As early as in the early days of New China, the party has proposed to explore the laws of socialist construction and development issues. In 1956, Comrade Mao Zedong made his famous "On the Ten Relations", which emphasized in the development process to correctly handle contradictions among the people. We should properly handle the relationship between the various aspects to be "balanced, appropriate arrangements", emphasizing the development of purpose is "the people", focusing on mobilizing all positive factors, making a series of important theoretical perspectives on the development of socialist construction, preliminary exploration of the path of development in line with our situation. Eight party, based on a comprehensive analysis of the situation at home and abroad, pointed out that the main contradiction in our society is the people's economic and cultural needs of the rapidly growing economy and culture with the current situation that does not meet the contradiction between the needs of the people. It stressed the need to focus on the development of social productive forces to achieve the country's industrialization.

At the core of Comrade Jiang Zemin of the third generation of central collective leadership, it made the important thought of "Three Represents", which is emphasizing the development as the top priority in governing and rejuvenating the party, sticking with the development of methods to solve the problem. It is noting that "the development of new ideas new breakthroughs in reform, the work should have a new situation, "clearly put forward in the development of the socialist market economy to correctly handle the relationship between a series of major modernization, the proposed technology and education strategy of sustainable development, the western major strategic development strategy. Further on the "how to develop" made a scientific exploration, it enriches the theory and practice of socialist modernization. Comrade $\mathrm{Hu}$ Jintao is as general secretary of the CPC Central Committee, adhering to Mao Zedong, Deng Xiaoping and Jiang Zemin's important basis on development on the new reality. We should meet the needs of building a moderately prosperous society, focus on the development of the law to grasp the rich connotation of development, innovation and development concepts, pioneer the development of ideas, and solve development problems. We should further propose a complete scientific concept of development, a sign of our party understand the law of socialist modernization in greater depth and comprehensive.

In the "CPC Central Committee on perfecting the socialist market economic system, a number of issues," the party's Third Plenum clearly puts forward by the scientific concept of development, that is people-oriented, comprehensive, coordinated and sustainable development, and promotes comprehensive economic, social and human development. Under the new historical conditions, the scientific concept of development is to redefine the concept of development, rich, profound and comprehensive: the scientific development concept, the first prerequisite of the development of the core is people-oriented, comprehensive, coordinated and sustainable basic requirement of the fundamental approach is to co-ordinate taken into account.

There is a variety of development theory in the world, the world also in the practice of own development. Scientific concept of development is the latest achievements of modern Chinese social development for China to develop and realize what kind of development specified in the right direction, is in line with the fundamental interests of the masses and development requirements.

\section{NORMAL SITUATION - FAIR AND BALANCED DEVELOPMENT EFFICIENCY}

After 30 years of reform and opening up, China has solved the problem of food and clothing of 1.3 billion people. It can be said, compared with the beginning of the reform, China has basically gone through a survival-type stage of social development, society began to develop across the stage. At this point, the survival of the problem pressure is weakening, and developmental problems are more prominent, more and more pressure. Development issues are closely related to the vital interests of each individual, at any time, all must attach great importance to the issue. However, after the productive forces have made progress, development issues will be more prominent and manifested, request or demand for the development of people will be getting high, for the understanding of content development will require being more profound and comprehensive. If there is slightest mistake, seemingly development, but in reality it hides great crisis.

In November 1993, the Third Plenary Session of the 14th Party Congress "decision" is clearly the beginning of "giving priority to efficiency due consideration to fairness." This indicates that China has begun to highlight the efficiency. As we know, the efficiency is productivity. 2004 Plenary Session of the Party's Sixteenth "decision" from the height of building a socialist society balance, proposed to "focus on social justice," October 2005 Party Plenum in the "CPC Central Committee on tenth five-Year Plan for National Economic and Social Development proposal "clearly" more emphasis on social justice, so that all people share the reform and development. "In October 2007, Premier Wen Jiabao at the congress report has clearly pointed out again: "to achieve social equity and justice is the consistent stand of the Chinese communists, is a major task of developing socialism with Chinese characteristics". It is "to increase the material wealth of society through the development, continue to improve people's lives, but also through the development of guarantee social equity and justice and constantly promote social balance." Our government in understanding the relationship between fairness and efficiency perfect highlights our ability to govern with increasing levels of complexity and control environment building a moderately prosperous society in confidence.

Chinese leaders have repeatedly stressed that social fairness and justice in a socialist society are critical, indicating that there is a problem in dealing with the issue of equity and efficiency for our current development, which began to reflect on the question of the development process. 
Development of human society is nothing more than the satisfaction of human needs, and requires a final performance on efficiency and equity. We express the scientific development concept, the development of what we need is a good, high-quality development, this development is a fair and balanced development of the adaptability and efficiency, neglecting or detrimental to the development of equity and efficiency of any party is not real development, not the development of science. In other words, the development of science is to strive to achieve or maintain fair and balanced development efficiency. Only with fair, but no efficient development, it is not the development of science; also, only efficiency, it cannot guarantee a fair development, nor is the development of science. Fairness and efficiency neither are incompatible with each other nor harm the development of science. Scientific development is adaptive balance of fairness and efficiency. Fair is fair, based on efficiency, efficiency is the efficiency based on equity, fairness and efficiency must adapt, efficiency and fairness have to adapt. Efficiently and fairness, equity and efficiency are to adapt to each other rather than to harm the development, it is the development of science, it is the hope of the development of human society. Otherwise, the human society will go into a dilemma: not only the relationship between people and even in tense confrontation and the relationship between people and nature will also be in a state of tension and even confrontation.

We should not ignore it; history has given us a clear answer. The lessons of history are cruel and profound. Indonesia had occurred in social unrest, a direct result of the government's downfall. The reason is mainly due to economic and social development out of balance, the income gap between rich and poor strata of the population polarization. The national long-term importance neglects economic development, social development, it only values GDP, cares of social security; it is an important source of social crisis of its occurrence. In other words, for the same reason, the Government of Indonesia operations pursued the "Bible" that is efficiency, and serious damage to the fair, there has been a serious imbalance between fairness and efficiency, which led to many social problems. These social problems are deeper and spread to the household and community levels, a wide range of families and communities to begin the government's legitimacy has been questioned, and it is inevitable that political unrest occurred. As another example, in Brazil in 2002, per capita GDP exceeds \$3,000, the urbanization rate reached $82 \%$, but they accounted for $34 \%$ of the poor national population. One side is a modern, while it has had so many poor people; there is growth without development, and most people do not enjoy the fruits of modernization.

Now, China's economic and social development has entered a critical period. The key reason for this critical period is that what we are facing at this time is facing some serious long-term conflicts and problems, such as environmental problems, the wealth gap, resource and energy shortages, and so on. Our energy consumption per unit of GDP is 3.3 times of Canada, the United States, 4.3 times, 8.6 times that of Italy, Japan, 11.5 times, while sulfur dioxide emissions per $\$ 1000$ GDP is eight times of the United States, Japan, 61,6 times. Scholar Wu Zhongmin frankly pointed out that although some Chinese society with justice related parts also made some significant progress, but what cannot be denied is that Chinese society appeared worrying problem in many aspects of justice. In the very large extent offset by the fruits of development, then for safety and healthy development of Chinese society have had a very negative impact.

What we want is to continue to meet the development, in line with both fairness and efficiency, and to maintain a balance between fairness and efficiency. Our society is in the fairness and efficiency from balanced to unbalanced, then from unbalanced to balanced, so that a continuous cyclical process of adaptation in continuous development and improvement. As Marx in April 14, 1856, pointed out in the Chartist newspaper "De Volkskrant": "In our time, it seems to have a thing for each that contains its own opposite, we see machines. With reduced human labor, we make labor more productive magic, but it has caused starvation and excessive fatigue. The new source of wealth, because of some strange, incredible magic and become a source of poverty. Triumph of technology, it seems based on the moral corruption of a price. With the increasingly humankind masters nature, man seems to become someone else's slave or slaves of their own despicable behavior. Even the pure light of science seems to have only ignorant dark background shine. We all found and progress seems to be the result of physical force to make intelligent life, and human life is dull into a material force. "

\section{CONCLUSIONS}

Economic development is the last word, fair social development is the last word, and the last word of a socialist society is to adapt to balance efficiency and fairness of social development. Scientific development is the fairness and efficiency to adapt to balanced development, equity and efficiency with adaptive balanced development is truly to reflect the scientific concept of development, is the norm in China's economic and social development. Only economic development or only social development without fairness should not have developed socialist society.

\section{References:}

[1] [US] Joshua Cooper Ramo Beijing Consensus [A] turn Yellow Ping China and Globalization: Washington Consensus or the Beijing Consensus [C] Beijing: Social Sciences Academic Press, 2005 : 25.

[2] Sun Zhengyu. Theory and practice and the dialectical relationship between [N]. Guangming Daily, 2009-11-24 (11).

[3] Marx and Engels, Marx and Engels, Selected Works (Volume 2) [M]. Beijing: People's Publishing House, 1995: 11.

[4] Cong Xiaofeng. Social Justice and Social Progress Research Issues [M] Jinan: Shandong People's Publishing House, 2005 (10): 13.

[5] Marx and Engels, Marx and Engels, Selected Works (Volume 1) [M]. Beijing: People's Publishing House, 1995: 775. 